Presenters: ${ }^{1}$ Ferederieke G Schaafsma, ${ }^{2}$ Eun A Kim, ${ }^{3} \mathrm{~T}-\mathrm{J}$ Cheng, Lode Godderis ${ }^{4}$

${ }^{1}$ VU University Medical Centre, Amsterdam, The Netherlands

${ }^{2}$ Occupational Safety and Health Research Institute, KOSHA, Ulsan, Republic of Korea

${ }^{3}$ Chi Mei Medical Centre, Tainan, Taiwan

${ }^{4}$ KU Leuven, Leuven, Belgium

\section{2a PRE-EMPLOYMENT EXAMINATIONS FOR PREVENTING INJURY, DISEASE AND SICK LEAVE IN WORKERS}

Ferederieke G Schaafsma. VU University Medical Centre, Department of Public and Occupational Health, Amsterdam Public Health Research Institute, Postbus 7057, Amsterdam, 1007 MB, The Netherlands

\subsection{6/oemed-2018-ICOHabstracts.455}

Introduction To evaluate the effectiveness of pre-employment examinations of job applicants in preventing occupational injury, disease and sick leave.

Methods We systematically searched in medical databases for randomised controlled trials, controlled before-after studies, and interrupted time-series studies up to March 2015.

Result Nine studies evaluated the screening process as a whole. Two studies evaluated measures to mitigate the risks found following the screening process. The studies were too heterogeneous for statistical pooling of results.

There is very low quality evidence based that a general examination for light duty work may not reduce the risk for sick leave (MD $-0.09,95 \% \mathrm{CI}:-0.47$ to 0.29 ). For army recruits, there is very low quality evidence that there is a positive effect on fitness for duty after 12 months follow-up (OR 0.40, 95\% CI: 0.19 to 0.85 ).

There is inconsistent evidence of an effect of job-focused pre-employment examinations on the risk of musculoskeletal injuries in comparison with general or no pre-employment examination. There is very low quality evidence that incorporation of a bronchial challenge test may decrease occupational asthma (trend change $-2.6,95 \% \mathrm{CI}$ : -3.6 to -1.5 ) compared to a general pre-employment examination with lung function tests. In six out of seven studies, the rates of rejecting job applicants increased because of the studied examinations.

There is very low quality evidence that risk mitigation among applicants considered not fit for work may result in a similar risk of work-related musculoskeletal injury during follow-up compared to workers considered fit for work.

Conclusion This evidence supports the current policy to restrict pre-employment examinations to only job-specific examinations. Better quality evaluation studies on pre-employment examinations are necessary, including the evaluation of the benefits of risk mitigation, given the effect on health and on the financial situation for those employees who do not pass the pre-employment examination.

\section{$1702 \mathrm{~b}$ LESSONS FROM THE EXPERIENCE OF WORKERS' MEDICAL EXAMINATION IN KOREA}

Eun A Kim. Occupational Safety and Health Research Institute, Kora Occupational Safety and Health Agency, Ulsan, Republic of Korea

10.1136/oemed-2018-ICOHabstracts.456
Since 1972, workers exposed to the specific risk factors at workspace have been received annual medical check-up in Korea. The number of medical examinees has increased from 800000 in 1972 to 2,000,000 in 2016 with expansion of the working population and the risk factors listed by the regulation. Recently, approximately 500 occupational physicians and 150 medical institutes are participated in this system.

The risk factors have been increasing along with the new scientific findings. There were 31 kinds of risk factors that employers should provide to their employees. They increased to 122 kinds in 1999, and 177 in 2005. Since 2014, health examination to night shift workers has introduced because night shift work can be a risk factor of cardiovascular diseases, insomnia, and gastro-intestinal disorders.

Recently, the diagnosis rate of occupational diseases detected by the health examination is very row (lesser than $0.1 \%$ ) which is not appropriate for screening on mass medical examination. We also do not have the scientific evidence regarding effectiveness of the workers' medical examination system for preventing of occupational diseases. However, the system has an important role of surveillance for health condition by exposure to hazardous substances and of providing occupational health services with the medical test results. Moreover, the opportunity of the annual health check-up of small sized industries is still valuable for detecting workrelated diseases and life style diseases as well, which justifies the good reason for performing the periodic medical examination.

The purpose of the workers' medical examination at the beginning was not only limited to the early diagnosis of occupational diseases, but the basic information of occupational health services at workplace. The medical examination system should be amended continuously to accomplish the both purposes: early diagnosis (screening) and occupational health services (promotion).

\section{C PERIODIC HEALTH EXAMINATION FOR WORKERS IN TAIWAN}

1,2T-J Cheng, ${ }^{3,4} \mathrm{H}-\mathrm{R}$ Guo. ${ }^{1}$ Department of Neurology and Occupational Medicine, Chi Mei Medical Centre, Tainan, Taiwan; ${ }^{2}$ Department of Hospital and Health Care Administration, College of Recreation and Health Management, Chia Nan University of Pharmacy and Science, Tainan, Taiwan; ${ }^{3}$ Department of Occupational and Environmental and Health, National Cheng Kung University, Tainan, Taiwan; ${ }^{4}$ Department of Occupational and Environmental Medicine, National Cheng Kung University Hospital, Tainan, Taiwan

\subsection{6/oemed-2018-ICOHabstracts.457}

In Taiwan, the Labour Health Protection Regulation is implemented on the basis of Occupational Safety and Health Act. The Regulation mandates employers arrange screening health examinations for employees before starting to work and also lists 12 categories of special health examinations targeting at jobs with exposure to special health hazards such as ionising radiation, noise, lead, etc. Workers who have certain diseases and conditions are not allowed to engage in certain categories of jobs. Employers are required to conduct a health examination on workers who are under 40 years of age every five years. For those who are between 40 and 65 years of age, health examinations should be conducted every three years, and for those who are above 65 years of age, every year. For workers who were engaged in the hazardous jobs listed by the Regulation, the health examination should be conducted 
annually regardless of their ages, and the costs are paid by the Bureau of Labour Insurance (BLI). After each periodical examination on a worker engaged in a hazardous job, physicians need to assign the results to one of the four levels of management (Level 1, 2, 3 and 4). For workers with a management level of 2 or above, physicians need to make notes of the jobs that should be avoided and precautions that should be taken. Furthermore, for workers with a management level of 3 or above, physicians need to make diagnoses on the basis of the test results. All the health examinations are performed by health-care institutes accredited by BLI, and health-care institutes are required to report cases with a management level of 3 or above to both to the inspection authority. Therefore, the health examination system also serves as a part of the reporting system of occupational diseases and injuries in Taiwan.

\section{2d EFFECTIVENESS OF PERIODICAL MEDICAL EXAMINATION TO PREVENT WORK-RELATED ILL- HEALTH} ${ }^{1,2}{ }^{2}$ Lode Godderis, ${ }^{3} J o n a s$ Steel, ${ }^{3,4}$ Jeroen Luyten. ${ }^{1}$ Environment and Health, Department of
Public Health and Primary Care, KU Leuven, Belgium; ${ }^{2}$ IDEWE, External Service for
Prevention and Protection at Work, Belgium; ${ }^{3}$ Leuven Institute for Healthcare Policy, Faculty
of Medicine, KU Leuven, Belgium; ${ }^{4}$ Department of Social Policy, London School of
Economics and Political Science, UK

\subsection{6/oemed-2018-ICOHabstracts. 458}

Introduction Periodic health examinations (PHE) have been a fundamental part of occupational health and safety (OHS) practice for decades. Nonetheless, PHE have not received a great deal of attention in health economics and ethics literature, which poses many interesting challenges from an efficiency and an equity perspective.

Methods We performed electronic searches in databases as EMBASE, PUBMED and Cochrane Library from September 2007. Search terms included MeSH, EMTREE and free text terms related to economic evaluation, occupational health intervention and productivity. We independently included all studies based on three criteria:

1. the analysis was a full or partial economic evaluation (cost analyses);

2. included OHS interventions targeted at an employed population; and

3. were written in English, French, or Dutch.

Results The best available evidence assessing benefits of OSH interventions consisted of 156 economic evaluations. A broad range of intervention types was studied in the literature, most frequently health promotion (27\%), or multiple intervention types within one study (31\%). However, none of these studies specifically focussed on PHE. Studies mainly came from Europe (39\%) and North-America (51\%), and originated in diverse sectors and industries, most frequently health care $(15 \%)$

Conclusions Determining the value of OHS proved a theoretically complex endeavour and there are hardly data available on the value of PHE. While the majority of OHS interventions had positive conclusions, most studies were conducted in similar settings and showed substantial methodological deficiencies. Consequently, we need to be cautious to transfer results across settings or countries. Nonetheless, we rendered valuable insight into the potential cost-effectiveness of PHE and key-elements to design a high-quality study. We have now set up a study in Belgium comparing short-, medium- and long-term outcomes in employees undergoing PHE, with a group without an intervention.

\section{PREVALENCE OF OCCUPATIONAL EXPOSURE TO RESPIRABLE CRYSTALLINE SILICA IN THE METAL WORKING INDUSTRIES: TRANSFERRING RESEARCH INTO INDUSTRIAL PRACTICE}

Cláudia Fernandes*, Cláudia Ribeiro, Rita Aguiã, Mónica Henriques. CATIM - Technological Centre for the Metal Working industry, Porto, Portugal

\subsection{6/oemed-2018-ICOHabstracts.459}

Introduction The exposure to respirable crystalline silica (RCS) in some industrial processes within the metal working industry is a recognised occupational hazard, mainly due to the classification of RCS as a group 1 carcinogen to the respiratory system, and the severity of the exposure consequences.

Methods This study was conducted based on the determination of the concentration of airborne RCS particles and the evaluation of its risk level among metal workers placed in 15 industrial SME's and 130 workplaces. The study was conducted in two industrial processes:

i. foundry;

ii. other processes with the exposure risk.

Occupational personal exposure to RCS was measured in all workers exposed using the NIOSH method 7500.

Result The range of RCS concentrations are:

i. global sample is $1,159 \mathrm{mg} / \mathrm{m}^{3}-\left(0,006 \mathrm{mg} / \mathrm{m}^{3}\right)$;

ii. foundry $0,093 \mathrm{mg} / \mathrm{m}^{3}$;

iii. other processes $0,018 \mathrm{mg} / \mathrm{m}^{3}$.

For the 130 workplaces monitored, 82 were higher than the permitted limit recommended by the Standard NP 1796: 2014. The processes with higher risk of exposure are those within 'pure foundry' such as metal melting, casting, sand moulding, pouring and repairing furnace.

Discussion The average concentrations of RCS for the assessed workplaces were higher than the exposure limits by NP 1796:2014. An intervention plan for each SME was designed encompassing measures at different levels aiming the promotion of health and wellbeing in the workplaces. Due to the severity of the exposures consequences urgent actions must be taken in the workplaces. The inclusion of measures that go beyond the definition of 'simple' personal protective equipment (PPE) are needed to raise the level of prevention. Such interventions are well seen by SME but conditioned by operational and budgeting issues. The information on this study, about occupational processes and individual tasks and the corresponding levels of RCS exposure can guide future needs for intervention in critical areas.

\section{AN INTERVENTIONAL STUDY TO ASSESS THE INCIDENCE OF VITAMIN B12/D3 DEFICIENCY AMONG CORPORATE EMPLOYEES}

${ }^{1}$ Amar Kapadia, ${ }^{1}$ Aditya Paliwal, ${ }^{2} \mathrm{R}$ Rajesh. ${ }^{1}$ Reliance Industries Ltd, Hazira Manufacturing Division, Surat, India; ${ }^{2}$ Reliance Industries Ltd, Mumbai, India

10.1136/oemed-2018-ICOHabstracts.460 